\title{
Revista de Psiquiatria Clínica no iPad
}

\section{Revista de Psiquiatria Clínica in the iPad}

É com satisfação que anuncio que, a partir de agora, o conteúdo da Revista de Psiquiatria Clínica (RPC) também estará disponível em formato de aplicativo para tablets iPad.

Já em 1996, quando assumimos a edição da RPC, inserimos seu conteúdo na internet, criando para isso um site próprio. Desse modo, nosso periódico tornou-se uma das primeiras revistas médicas do mundo a oferecer acesso aberto (open access) à comunidade. Alguns anos depois, a Revista passou a ser oferecida também no site da SciELO, aumentando, assim, a abrangência de sua divulgação científica.

Com a versão para iPad, a RPC torna-se um dos primeiros jornais psiquiátricos do mundo e um dos primeiros jornais científicos brasileiros a oferecer esse recurso. A versão para iPad apresenta vantagens, como interação com redes sociais e envio de matérias por e-mail.

Para obter o aplicativo, siga os seguintes passos:

1. entre na Apple Store via seu iPad;

2. acesse a categoria "medicina";

3. procure por "Revista de Psiquiatria Clínica" no campo de busca acima à direita;

4. faça o download gratuitamente;

5. faça um cadastro simples para ter acesso às publicações;

6. caso você tenha problemas com esse download, solicite ajuda pelo e-mail rpc@segmentofarma.com.br

Indexada no Institute for Scientific Information (ISI), a RPC é o periódico psiquiátrico com o maior fator de impacto entre os publicados em língua portuguesa e o sexto do mundo em língua não inglesa. A versão para iPad ampliará sensivelmente o acesso mundial às matérias publicadas na RPC. Com isso, além de contribuir para nossa missão informativa, tornaremos a RPC mais atraente para nossos autores, dando uma maior divulgação para suas contribuições científicas. Esperamos que o resultado final seja melhorar ainda mais a excelência dos trabalhos submetidos para publicação.

Desejo a você que esse novo meio de leitura da RPC seja uma ótima experiência.

Wagner Farid Gattaz

Editor-chefe 